\title{
The relationship between quality of learning experiences and academic burnout among nursing students of Shahid Beheshti University of Medical Sciences in 2015
}

\author{
Zohreh Aghajari ${ }^{1}$, Laleh Loghmani ${ }^{2}$, Mahnaz Ilkhani ${ }^{3}$, Atefe Talebi ${ }^{3}$, Tahere Ashktorab ${ }^{3}$, Mehrnaz Ahmadi ${ }^{1}$ \\ Fariba Borhani ${ }^{4}$
}

\begin{abstract}
Introduction: While attending in university have pleasant experiences for many students, academic activities will lead to academic burnout for some of them. Obviously, academic burnout will have negative effects on mental, psychological and physical well-being of students. The purpose of this study was to determine the relationship between quality of learning experiences and academic burnout among nursing students of Shahid Beheshti University of Medical Sciences in 2015.

Method: This descriptive-correlational study was conducted on 223 nursing students of Shahid Beheshti University of Medical Sciences in Tehran. The samples were selected by quota and then convenience sampling method, and demographic and educational questionnaires, Newman's quality of learning experience questionnaire and Bersow's academic burnout inventory were completed by subjects. Data were analyzed by descriptive and analytical methods such as correlation coefficient, independent t-test, one-way ANOVA and multiple linear regression.

Results: The results showed a significant negative correlation between the quality of learning experiences and academic burnout ( $r=-0.18 ; p: 0.006)$, and the subscales of these two variables, with the most relationship was found between lack of academic interest and the content of the curriculum ( $r$ $=-0.22 ; \mathrm{p:} \mathrm{0.001)}$. By entering the main and underlying variables to multivariate linear regression model in step-by-step method, the student's interest in the field of study before entering the university and the mean score were known as the explanatory factor for academic burnout.

Conclusion: Academic burnout of students can be influenced by the quality of their learning experiences. But this connection may indirectly be influenced by underlying factors such as academic performance and general interest in the field.
\end{abstract}

Keywords: quality of learning experiences, academic burnout, nursing students

\section{INTRODUCTION}

Nursing education today faces complexities in both theoretical and clinical education. Students as recipients of educational services are the best source for identifying educational problems because they have direct and immediate interaction with this process (1). While attending the university for many students has pleasant experiences, for some of them, educational activities such as quizzes, articles, curriculums and other assignments will lead to academic burnout. Obviously, academic burnout will have negative effects on mental, psychological and physical well-being of students (2).

In psychology, the term burnout refers to multi-factor syndrome consisting of emotional exhaustion, depersonalization, and diminished individual's sense of adequacy $(3,4)$. Emotional exhaustion is a feeling of being under pressure and losing affective and emotional resources in one person. Depersonalization is a negative and harsh response to people who are usually recipients of service from the individual and refer to the pessimistic attitude and negative perception of the individual from his/her client. Reducing individual adequacy is a diminution of sense of competence

\footnotetext{
Students Research committee, School of Nursing and Midwifery, Shahid Beheshti University of Medical Sciences, Tehran, Iran.

2 Assistant Professor, School of Nursing and Midwifery, Bam University of Medical Sciences, Bam, Iran.

3 Department of Medical Surgical Nursing, School of Nursing and Midwifery, Shahid Beheshti University of Medical Sciences, Tehran, Iran.

4 Department of Medical Surgical Nursing, School of Nursing and Midwifery, Medical Ethics and Law Research Center, Shahid Beheshti University of Medical Sciences, Tehran, Iran
}

\begin{abstract}
Correspondence: Fariba Borhani
Department of Medical Surgical Nursing, School of Nursing and Midwifery, Medical Ethics and Law Research Center, Shahid Beheshti University of Medical Sciences, Tehran, Iran
\end{abstract}

E-mail:faribaborhani@msn.com

Received: 15 Feb 2018, Accepted: 11 May 2018

(C) 2018 by the authors; licensee Modestum Ltd., UK. This article is an open access article distributed under the terms and conditions of the Creative Commons Attribution License (http://creativecommons.org/licenses/by/4.0/). 
in performing a personal task and is a negative self-assessment of doing work, especially with regard to customer service, and feeling discomfort and dissatisfaction with his or her career achievements $(5,6)$. Burnout is now considered as a public health problem, because in addition to economic and social costs, endangers people's physical and mental health as well (7).

Burnout was first introduced in jobs that are directly related to people and provided services, and emphasized the relationship between the service provider and applicant (8). Nowadays, this variable has expanded to educational situations and textures, referred to as academic burnout (9). Academic burnout is defined as a feeling of tiredness due to the demands and requirements of studying (fatigue), having a pessimistic feeling and without interest in the content and tasks (pessimism and lack of interest), and the feeling of poor personal development in curriculum and education (reduced personal self-efficacy) (10). In other words, academic burnout is a feeling of inferiority and mental fatigue that students exhibit against chronic stress due to lack of resources to perform their tasks and duties (11).

Previous studies have shown that students have a moderate upward level of burnout (11, 12 and 13), and this burnout is increasing during the course of study (14), so that the results of the study by Rudman and Gustavson (2012) indicated $10 \%$ increase in the degree of academic burnout of Swedish nursing students during the course of study, which in addition to reducing academic engagement, has had an impact on the future job performance of a person (15). It was also shown that academic burnout has positive relationship with depression, low quality of academic performance, sense of monotonousness, self-deficiency and preventive strategies of success and a negative relationship with academic engagement and self-confidence (10). Duran et al. (2006) found a positive and significant relationship between the perceived stress and the academic burnout of Spanish students (16).

Based on research on academic burnout, a wide range of symptoms and complications of poor academic performance such as: lack of eagerness to curriculum and continual presence in classrooms, frequent absenteeism, lack of participation in classroom activities, feeling meaningless in academic affairs and inability to learn lessons and even dropouts to physical and psychological complications such as headaches, abdominal pain, sleep disorders and nutrition and physical activity, feelings of fear and depression, alcohol and drug abuse, and even impairment in the quality of work performance $(5,15,17,18$ and 19$)$.

Education and learning is a stressful experience, especially in the field of nursing, which students in addition to the stress of theoretical education face with several other stressors such as unpleasant clinical experiences, observing the mortality of patients, observing the pain and suffering of people, humiliating experiences, fear of mistakes on the patient's bedside, dealing with a variety of dangerous and contagious diseases, the instructor's attention in the presence of the patient, the relationship with other staff in clinical settings, and the need to learn a variety of skills and knowledge for different and widespread roles (20,21, and 22); and sustained stress is one of the main causes of burnout (12).

One of the main causes of the global shortage of nurses is the high rate of erosion in nurses and nursing students associated with stress and burnout. Today, this issue has been given special attention in research (14) and identification of predictors of burnout is one of the main issues in this field. Based on the requirements-sources model presented by DeMorty et al. (2001) in explaining the job burnout indicating imbalance between needs and job demands with job resources, the basic assumption of the present study is that academic burnout among students can be affected by learning situations that, on the one hand, there is academic requirements and stress associated with it and, on the other hand, it does not provide the necessary support mechanisms that facilitate the matching process for the student (18).

In educational environments, students are faced with many educational needs and resources that can affect the interaction or academic burnout and individuals' general welfare of (10). Therefore, one of the variables that may be related to academic burnout is the quality of learning experiences. The term "quality of learning experiences" was first introduced by Newman (1990) and refers to students' perceptions of direct and indirect inputs obtained from their college (18). Direct inputs mean investments of the college in the curriculum in terms of content, resources and flexibility; while indirect inputs include the processes by which the colleges try to increase learning, for example, student-college contact and inner engagement in academic programs and assistance in active student learning (12).

Newman et al., in their extensive studies on students' learning and academic achievement in the 1990s, extracted several factors related to the quality of learning experiences affecting performance and academic outcomes (durability, graduation, academic satisfaction, and commitment to education) (23). According to Newman, the quality of learning experiences is influenced by the content of education, resources, curriculum flexibility, and the quality of teacher-student relations. Enriching learning experiences by creating opportunities for learning and content and appropriate resources and paying attention to active learning that affects students' mental activity in coping with the challenges posed by learning situations can have a significant effect on the student's academic and professional development (24). Therefore, 
academic burnout, which is a response to learning difficulties facing the student with the pressures associated with academic performance, can be the result of a mismatch between the educational and personal resources and their expectations and others' expectations for academic achievement (25).

According to the studies conducted in the area of research related to the quality of learning experiences and academic burnout, a study investigated the quality of learning experiences and their role in nursing students' academic burnout, was not found. While nursing students, due to the nature of their discipline and their special needs and sensitivities, seem to have different learning experiences than other non-clinical courses, and the risk of burnout is higher in them. Therefore, the present study was conducted to assess the quality of learning experiences and academic burnout and the relationship between these two categories in nursing students. Obviously, as long as the physical and mental well-being and the performance of students are concerned with the educational system, understanding the development and growth of academic burnout is worth further research.

\section{STUDY METHOD}

This is a descriptive-correlational study in which 223 undergraduate nursing students studying at the Faculty of Nursing and Midwifery of Shahid Beheshti University of Medical Sciences in Tehran during the second semester of academic year of 2014-2015 were studied. To this end, after obtaining the total number of undergraduate nursing students from the second semester up based on graduate level from the Department of Education, using the proportion and sample size obtained from the statistical formula, the number of samples was determined in each semester, then convenience sampling method was used in each class. The reason for not choosing semester one students (freshman) was less exposure to erosion conditions and less involvement with homework and academic requirements. In addition, having Iranian nationality, having no mental problems needed treatment in the last six months and severe and chronic physical problems or disabilities, experiencing a major recent stress such as the death of loved ones, divorce, etc and according to individual statements, were conditions for admission to participate in this study. Guest students were also excluded from this study. The tool were demographic information form, Newman's learning experience quality questionnaire and Bersow's academic burnout inventory that were completed by participants before the beginning of the classroom or in clinical settings during the student's leisure time with accepting permission from the professors and trainers and the presence of the researcher and the presentation of the necessary explanations. The demographic information form includes variables such as age, gender, place of residence, marital status, number of children, employment status, income level and academic information such as semester, enrollment quota, and the average of all past semester.

The Newman's learning experience quality questionnaire was made by Newman (1990) and Neami (2009) used it in Iran. This questionnaire consists of four domains: 1- Resources (two items) 2- Content (four items) 3- Learning flexibility (two items) and 4- The quality of formal and informal relations between professors and students (four items). Each item is scored as 5-point Likert from very weak (score 1) to very good (score 5). The score ranged between 12 and 60 . Newman obtained the reliability coefficients for the four domains of this questionnaire $0.71,0.74,0.86$ and 0.91 respectively. In Neami's research (2009), the internal consistency coefficients of the four domains were calculated to be $0.86,0.79,0.85$ and 0.82 , respectively, using Cronbach's alpha method, respectively. In this study, Cronbach's alpha for the total score of the quality of learning experiences was 0.86 , and for the four areas of resources, content, learning flexibility, and studentprofessor relationship were $0.81,0.74,0.70$ and 0.84 , respectively.

Academic burnout inventory was developed by Bersow et al (1997) to measure three areas of academic burnout, namely academic fatigue, academic unwillingness and academic inadequacy. The mentioned inventory has 15 items, which using 5-point Likert rating method has been scored from completely disagree (score 1) to the completely agree (score 5). Academic fatigue includes 5 items, academic unwillingness 4 items and academic inadequacy 6 items. Of course, given the fact that the academic efficiency scale (i.e. positive sentences) has been used for the recent domain, the sentences of this domain are scored in reverse order. The reliability of the inventory was calculated by its creators $0.70,0.82$ and 0.75 for three areas of academic burnout, respectively. Neami (2009) obtained reliability for academic fatigue of 0.79 , for academic unwillingness of 0.82 and for educational inadequacy of 0.75 . In the present study, Cronbach's alpha for total score of 0.75 was calculated and $0.71,0.75$ and 0.70 respectively for three levels of academic fatigue, academic unwillingness and academic inadequacy.

Data were analyzed by SPSS software version 22. Statistical analysis was done in descriptive and inferential sections. To describe the quantitative data central and dispersion indices such as mean and standard deviation were used and to describe qualitative data frequency tables including absolute frequency and frequency percentage were used. In the 
Table 1: Association between different components of the quality of learning experience and academic burnout

\begin{tabular}{lccccc}
\hline & Quality of Learning Experience & Resources & Content & Flexibility & Relationship \\
\hline Burnout & $-0.18(0.006)$ & $-0.08(0.217)$ & $-0.20(0.002)$ & $-0.13(0.054)$ & $-0.13(0.054)$ \\
\hline Exhaustion & $-0.135(0.04)$ & $0.04(0.53)$ & $-0.16(0.015)$ & $-0.14(0.03)$ & $-0.125(0.063)$ \\
\hline Cynicism & $-0.20(0.003)$ & $-0.128(0.057)$ & $-0.22(0.001)$ & $-0.09(0.19)$ & $-0.13(0.046)$ \\
\hline Inefficacy & $-0.12(0.07)$ & $-0.11(0.112)$ & $-0.12(0.09)$ & $-0.01(0.84)$ & $-0.062(0.358)$ \\
\hline
\end{tabular}

analytical section, a single-variable analysis was first performed. To determine the correlation between the quality of learning experiences and academic burnout, as well as with other quantitative variables, Pearson correlation coefficient was used if there were any test conditions and Spearman's correlation coefficient was used in the absence of conditions. Independent t-test was used to compare the quality score of learning experiences or academic burnout in two-way qualitative variables (sex, marital status, admission status and number of children) considering the establishment of parametric test conditions. One-way ANOVA was used to compare the quality score of learning experiences or academic burnout in three or more qualitative variables (such as academic semester, degree of interest in the field, residence and employment status). In multivariate analysis, multiple linear regression models were used to examine the relationship between academic burnout and the quality of learning experiences and other independent variables. Variables that were significant in the single variable stage or in boundary were entered into the model. The significance level was considered 0.05 .

\section{FINDINGS}

223 undergraduate nursing students participated in this study, including 122 (54.7\%) women and 101 (45.3\%) men. Among them, $16.6 \%$ were studying in the second semester, $11.7 \%$ in the third semester, $15.2 \%$ in the fourth semester, $17 \%$ in the fifth semester, $17.9 \%$ in the sixth semester, $9 \%$ in the seventh semester and $12.6 \%$ in the eighth semester. $99.1 \%$ of them were admitted to the national quota. $58.7 \%$ of the participants with a modest interest and $22 \%$ with low interest entered in nursing. 57.8\% were living with family and the rest in dormitory. $88.8 \%$ were single and the rest were married. $6.2 \%$ had children. $64.6 \%$ were unemployed, $31.8 \%$ had jobs related to the field and $6.3 \%$ had jobs that were not related to the field of nursing. The mean and standard deviation of participants' age was $21.93 \pm 2.4$ and the mean and standard deviation of their GPA (Grade Point Average) was $15.79 \pm 1.30$. The mean and standard deviation of the total income of participants was $6121500 \pm 3284300$ Rials and in the employed participants was $7102100 \pm 9270900$ Rials. The average score of the quality of the learning experiences of the students studied was 35.16 and the mean score of academic burnout of the students was 44.20 .

In the correlation between the quality of learning experiences and the academic burnout of the students, there was a negative and significant correlation between these two variables $(p=0.006, r=-0.86)$. Also, in the correlation between the domains of the two main variables, the quality of learning experiences and academic burnout with each other, academic fatigue with learning content and learning flexibility, and academic unwillingness had a significant negative relationship with other areas of quality of learning experiences, except for learning flexibility. The most correlation was related to academic unwillingness with the content of the curriculum $(p=0.001, r=-0.22)$ (Table 1).

In the study, there was no significant relationship between the quality of learning experiences with the variables of gender, age, grade, admission status, occupational status and place of residence of the students. However, there was a significant relationship between variables such as marital status, number of children, semester of education and interest in the relationship $(p<0.05)$. This means that, the mean of quality of learning experiences in married people was more than single students. Also, quality of learning experiences mean was more in students without children (Table 2). 
Table 2: The quality of learning experience according to baseline characteristics

\begin{tabular}{|c|c|c|}
\hline Item & Total score & p-value \\
\hline Gender & & 0.80 \\
\hline Men & $35.04 \pm 6.30$ & \\
\hline Women & $35.26 \pm 7.02$ & \\
\hline Marital status & & 0.049 \\
\hline Single & $34.85 \pm 6.46$ & \\
\hline Married & $37.64 \pm 8.03$ & \\
\hline Number of children & & 0.041 \\
\hline With children & $35.01 \pm 6.60$ & \\
\hline Without children & $40.67 \pm 7.21$ & \\
\hline Educational term & & 0.024 \\
\hline Two & $36.87 \pm 7.89$ & \\
\hline Three & $36.81 \pm 4.73$ & \\
\hline Four & $36.35 \pm 7.29$ & \\
\hline Five & $34.40 \pm 7.25$ & \\
\hline Six & $32.45 \pm 5.47$ & \\
\hline Seven & $36.65 \pm 6.41$ & \\
\hline Eight & $33.79 \pm 5.63$ & \\
\hline Level of interest to nursing & & 0.008 \\
\hline Low & $32.59 \pm 7.23$ & \\
\hline Intermediate & $35.74 \pm 6.41$ & \\
\hline High & $36.33 \pm 6.27$ & \\
\hline Type of residency & & 0.123 \\
\hline Living in dorms & $35.10 \pm 6.33$ & \\
\hline Living alone & $29.20 \pm 4.66$ & \\
\hline Living with family & $35.43 \pm 6.92$ & \\
\hline Occupation status & & 0.41 \\
\hline Unemployed & $35.03 \pm 6.51$ & \\
\hline Job related to nursing & $35.72 \pm 7.23$ & \\
\hline Job no unrelated to nursing & $32.50 \pm 4.17$ & \\
\hline
\end{tabular}

In studying academic burnout by demographic factors, the findings did not show a significant difference between academic burnout and gender, educational semester, place of residence and employment status. While there was a significant relationship between academic burnout and marital status, number of children, nursing interest in choosing a course, age and students' GPA score. As a result, single students and those with children experienced more burnout. Also, the mean score of academic burnout with GPA and interest rate in the nursing choosing the discipline and age was inversely related (Table 3). 
Table 3: The academic burnout according to baseline characteristics

\begin{tabular}{|c|c|c|}
\hline Item & Total score & p-value \\
\hline Gender & & 0.083 \\
\hline Men & $43.20 \pm 9.53$ & \\
\hline Women & $45.41 \pm 9.24$ & \\
\hline Marital status & & 0.023 \\
\hline Single & $44.71 \pm 9.22$ & \\
\hline Married & $40.16 \pm 10.37$ & \\
\hline Number of children & & 0.020 \\
\hline With children & $44.34 \pm 9.13$ & \\
\hline Without children & $39.33 \pm 18.20$ & \\
\hline Educational term & & 0.230 \\
\hline Two & $44.76 \pm 7.76$ & \\
\hline Three & $41.42 \pm 8.04$ & \\
\hline Four & $41.56 \pm 12.97$ & \\
\hline Five & $45.68 \pm 8.88$ & \\
\hline Six & $44.02 \pm 8.86$ & \\
\hline Seven & $46.70 \pm 10.54$ & \\
\hline Eight & $45.71 \pm 7.83$ & \\
\hline Level of interest to nursing & & $<0.001$ \\
\hline Low & $48.71 \pm 8.58$ & \\
\hline Intermediate & $43.52 \pm 9.14$ & \\
\hline High & $41.07 \pm 9.69$ & \\
\hline Type of residency & & 0.31 \\
\hline Living in dorms & $45.31 \pm 9.52$ & \\
\hline Living alone & $45.80 \pm 15.22$ & \\
\hline Living with family & $43.37 \pm 9.14$ & \\
\hline Occupation status & & 0.12 \\
\hline Unemployed & $44.21 \pm 8.50$ & \\
\hline Job related to nursing & $43.46 \pm 9.93$ & \\
\hline Job no unrelated to nursing & $50.75 \pm 17.65$ & \\
\hline
\end{tabular}

Table 4: Multivariate linear regression model to assess main determinants of academic burnout

\begin{tabular}{|c|c|c|c|c|c|c|c|c|c|c|c|}
\hline Predictor & $\mathbf{R}$ & $\mathbf{R}^{2}$ & Adj. $R^{2}$ & $\mathbf{F}$ & df1 & df2 & B & SE & $\beta$ & $\mathbf{t}$ & $p$ \\
\hline Model 1 & 0.28 & 0.07 & 0.07 & 18.95 & 1 & 221 & - & - & - & - & $<0.001$ \\
\hline Constant & - & - & - & - & - & - & 76.52 & 7.45 & - & 10.27 & $<0.001$ \\
\hline $\begin{array}{l}\text { Grade Point Average } \\
\text { (GPA) }\end{array}$ & - & - & - & - & - & - & -2.04 & -4.353 & -.281 & .470 & $<0.001$ \\
\hline Model 2 & 0.36 & 0.13 & 0.12 & 16.71 & 2 & 220 & - & - & - & - & $<0.001$ \\
\hline Constant & - & - & - & - & - & - & 79.97 & 7.310 & - & 10.94 & $<0.001$ \\
\hline $\begin{array}{l}\text { Grade Point Average } \\
\text { (GPA) }\end{array}$ & - & - & - & - & - & - & -1.83 & .461 & -.252 & -3.98 & $<0.001$ \\
\hline Interest & - & - & - & - & - & - & -3.42 & .935 & -.232 & -3.66 & $<0.001$ \\
\hline
\end{tabular}

The stepwise regression method was used to analyze the data. The findings showed that in the first model, the students' GPA score had the highest role in predicting the academic burnout of these students. The correlation coefficient of this variable with academic burnout was 0.28 and this variable could predict $7 \%$ of students' academic burnout. In the second model, after the student's GPA score, the student's interest has been entered in the equation. Correlation coefficient of these two variables with academic burnout was 0.36 and these variables predicted $13 \%$ of the students' academic burnout. Entering student interest rates could increase the predicted power by about $6 \%$. By accepting the order of entering variables in the second model and taking into account the standard beta of the variables entered in the regression equation, the student's GPA score with the standard beta equals to -0.252-plays a negative and most role in predicting the academic burnout of these students, then the students' interest rate with a standard beta of -0.232 has a negative and effective role in the academic burnout of these students. Finally, this model showed that the student's academic burnout increased by -1.8 per student for each decrease in their GPA score. Those who are more interested in study than those who have a modest interest and those who are modestly interested than those who have less interest reported -3.4 lower educational burnout rate (Table 4). 


\section{DISCUSSION}

The aim of this study was to determine the relationship between quality of learning experiences and academic burnout among nursing students of Shahid Beheshti University of Medical Sciences in 2015. The results of the study indicated that the mean score of the quality of the learning experiences of the students studied was moderate, which is similar to the findings of the study by Hayati et al. (2013) and Mazrogi et al. (2014) (12 and 13). These results reveal more effort in improving all aspects of the quality of learning experiences in universities, including providing easy access to educational resources, adapting the contents of academic courses to the professional needs of each discipline, the flexibility to provide educational content, changing the teaching style towards the student-centered and promoting the relationship between the teaching staff and the educational staff with students. Although, considering that much of the nursing student's experiences in clinical settings are in the clinical environment, the quality of learning experiences questionnaire may not fully cover the challenges of a clinical student's learning experience. Therefore, the necessity of doing further researches in this field is also felt.

The mean score of academic burnout among the students was moderate, which is consistent with the results of similar studies (2 and 13). However, the studies of Dasilva et al. (2014) and Thomas Kuwicksley Barlm et al. (2014) performed in Brazil showed a lower academic burnout in nursing students, which is different from the results of the present study (26, 27). This could be due to the difference in the tool used or to reflect the relatively better condition of nursing students in Brazil. Therefore, it is recommended to study the nursing education system, professional status and social status of this field and profession in such countries as compared to Iran.

In the study of correlation between the quality of learning experiences and academic burnout of the studied students, there was a relatively negative and significant correlation between these two variables. This finding is consistent with the results of studies conducted by Hayati et al. (2013) and Neami (2009) (12 and 18). Regarding the negative correlation between the quality of learning experiences with academic burnout and especially the academic unwillingness of the academic burnout variable, it is concluded that gradually, students will be bored and tired of doing things related to education as a result of mismatch between the components of learning experiences with their educational needs and their expectations and others for academic achievement.

There was also a significant negative correlation between academic burnout with curriculum content, the quality of teacher/student relationship and the quality of learning experiences, although according to the results, it seems that students' academic burnout is more influenced by the content of the lessons and is less influenced by the quality of formal and informal relations between students and professors, which is consistent with the study of Hayati and colleagues (2012) (12). While in the findings of the Neami's (2009) study the relationship between the teacher and student has the most role explaining the students' academic burnout (18).

The content of learning refers to the value and usefulness of educational materials. If the theoretical teachings, which are spent with energy and time, have little connection with the main goal of the field of study, and there is no possibility of their application and use, it causes fatigue and unwillingness in student, and consequently the decline in academic performance. Accordingly, Bransford et al. (1986) have put forward the term "useless knowledge ". Useless knowledge is a knowledge that is used only in limited situations. While fruitfully teaching requires knowing how to achieve information for learners so that they can relate them to other information, think about them, and apply outside the classroom (Neami 2009 quoted by Wilmingham 2003) (18). This issue becomes even more important in clinical practice, especially in nursing. A nursing student based on mental information puts into clinical settings and in the real environment and sensitive conditions associated with human health needs to take theoretical lessons into action. However, fear of errors and mistakes, along with other stressors in the clinical environment, provides the basis for academic burnout. Although the nature of nursing science and profession is based on a close relationship between theory and practice (28), according to researches, the main challenges of nursing in Iran and other countries are the gap between theory and practice (3129). Efforts to coordinate and integrate theoretical and practical trainings by nursing education planners will be an effective step in improving the teaching and learning process and preventing the students' academic burnout process.

Students have close links with the professors during their studies and the quality of this communication can have a profound effect on students' feelings and attitudes. The availability of professors and guidance and their assistance to students in order to carry out their duties will cause many existing stresses to be eliminated. Effective teacher relationship with student, counseling, feedback and positive reinforcement is important in educating students and creating a positive attitude towards their profession (32).

In the study of academic burnout in terms of demographic characteristics, the findings indicated that the academic burnout score is influenced by factors such as marital status, having a child, and the degree of interest in nursing in 
choosing a course. As a result, single students and those with children experienced more burnout. Also, the mean score of academic burnout with GPA score and interest rate in the field of nursing was inversely related to the choice of field and age. From the set of these results, it can be concluded that since married people are on a more specific path to their own lives, they are more likely to be on a favorable mental conditions than single people on the path to their education, but as the child enters the student's living conditions and with regard to important childbearing responsibilities, the educational problems of the individual increase and sometimes the interference of the various roles of marital life, career, being student and mismatches of a person with multiple roles can lead to students' academic burnout and loss of academic performance.

The results of multivariate regression showed the ability of "GPA score" and "student interest in nursing" to explain academic burnout choosing a course. Thus, students with a high GPA were at a lower level in terms of academic burnout, which is consistent with the result of study by Sharifi Fard et al. (2014), Mikaeli et al. (2012), and Durou et al. (2014) (4, 11 and 33), while is inconsistent with Rostami et al. (2011) indicating there is no relationship between the lack of a significant relationship between the students' GPA score and academic burnout (34). Perhaps the cause of the difference is related to the context of the university and the student's field of study. In general, a student with burnout is feeling frustrated, irritable and hopelessness, less interested and less motivating in lessons, and therefore has less academic performance (Mikaeli et al., 2012) (33) . However, the relationship between academic burnout and academic performance can be a two-way relationship. That is, as academic burnout can lead to decrease in academic performance and students' drop in GPA score, high academic performance can also be effective in reducing burnout by increasing self-confidence.

The interest in the field of study in students is one of the criteria for satisfaction and academic achievement that affects many of their affairs (Qarehaghaji and Ahadi, 2011) (35). However, the relationship of interest to the field of study with academic burnout can be rooted in the nature of the field of study, workload, responsibilities stress and interdisciplinary and inter-professional issues, scope of authority, career prospects and social status of the field. Therefore, it may be concluded that these factors can affect the academic burnout of students in a particular discipline by influencing their academic performance. Inadequate awareness of the goals of the nursing profession, the hard working conditions, and the inappropriate family look will cause a lack of motivation and interest in this profession (36). Attention to professional values in nursing can increase the awareness of nursing students with the goals of this profession and their interest in providing service to clients (37).

Therefore, it seems that in addition to measuring the scientific field in choosing a student for medical sciences, including nursing, which is related to human health, other criteria such as the assessment of volunteers' physical, mental, moral, and interest, motivation and attitude must be evaluated so that the most suitable people are led to this profession. Obviously, students with a stronger academic motivation will receive more training activities, they will do better homework assignments, resulting in more success. In addition, the interest in this profession is one of the preconditions for providing high quality services to clients.

\section{CONCLUSION}

According to the overall findings of this study, the inverse relationship between the quality of learning experiences and the academic burnout of students under the influence of the underlying factors of interest in the field of study and the GPA score, review of the content of general, basic and even specialized courses in nursing, further efforts to eliminate the gap between theory and practice, change in layout and distribution, and the distribution of curriculum materials during the course of study and flexibility in the choice of non-specific lessons and learning modes are felt. Also, the colleges' efforts to improve the quality and quantity of educational and research facilities, and the development of new educational and student-oriented practices, along with the assistance and guidance and interaction of professors in a safe environment and far from humiliation and threats, along with the sense of mutual trust and respect between the student and the professor, can play an effective role in creating and increasing students' interest and willingness in educational content. Undoubtedly, the reflection of these measures will increase the quality of professional services by increasing the academic performance, the desire to continue higher education in this field, preventing and reducing the students' academic burnout during the post-graduate and post-employment period. Considering the significant role of interest in the field of education in the incidence of academic burnout among undergraduate nursing students, providing solutions that can be effective in introducing and enhancing the real status of the nursing profession in terms of professional, spiritual, and material, in increasing the overall level of achievement in this field and profession is very important. 


\section{ACKNOWLEDGEMENTS}

This research was sponsored by Shahid Beheshti University of Medical Sciences in Tehran. Therefore, it is imperative for authors to acknowledge and appreciate all the units of this university and all the students participating in this research.

\section{REFERENCES}

1. Valizadeh S, Abedi HA, Zamanzadeh V, Fathi Azar E. Challenges of nursing students during their study, a qualitative study. Iranian Journal of Medical Education. 2007;7(2):397-407. [InPersian]

2. Behroozi N, Shahni Yelaq M, Pourseyed SM. Relationship between perfectionism, perceived stress and social support with academic burnout. Strategy for Culture. 2013;5(20):83-102. [InPersian]

3. Maslach C, Jackson SE. The measurement of experienced burnout. Journal of Organizational Behavior. 1981;2(2):99-113. https://doi.org/10.1002/job.4030020205

4. Duru E, Duru S, Balkis M. Analysis of relationships among burnout, academic achievement, and self-regulation. Educational Sciences: Theory \& Practice. 2014;14(4):1274-1284. https://doi.org/10.12738/estp.2014.4.2050

5. Cecil J, McHale C, Hart J, Laidlaw A. Behaviour and burnout in medical students. Medical Education Online. 2013;19:25209-25209. https://doi.org/10.3402/meo.v19.25209

6. Zis $P$, Anagnostopoulos F, Sykioti P. Burnout in medical residents: a study based on the job demands-resources model. The Scientific World Journal. 2014;(2014):1-10. https://doi.org/10.1155/2014/673279

7. Campos JADB, Maroco J. Maslach Burnout Inventory-Student Survey: Portugal-Brazil cross-cultural adaptation. Revista de Saúde Pública. 2012;46(5):816-824. https://doi.org/10.1590/S0034-89102012000500008

8. David AP. Examining the relationship of personality and burnout in college students: The role of academic motivation. Educational Measurement and Evaluation Review. 2010;1:90-104.

9. Bilge F, Dost MT, Cetin B. Factors affecting burnout and school engagement among high school students: study habits, self-Efficacy beliefs, and academic success. Educational Sciences: Theory \& Practice. 2014;14(5):17211727. https://doi.org/10.12738/estp.2014.5.1727

10. Salmela-Aro K, Upadyaya K. School burnout and engagement in the context of demands-resources model. British Journal of Educational Psychology. 2014;84(1):137-151. https://doi.org/10.1111/bjep.12018

11. Sharififard F, Nourozi K, Hosseini MA, Asayesh H, Nourozi M. Related factors with academic burnout in nursing and paramedics students of Qom University of Medical Sciences in 2014. Nursing Education. 2014;3(3):59-68. [InPersian]

12. Hayati $D$, Ogbahi $A$, Ahangari $H$, Azizi Abarghuei M. Investigating the relationships between quality of learning experience's components and self-efficacy on academic burnout among students of Allamme Tabatabaei University of Tehran. Educational Developement of Jundishapur. 2012;3(4):18-29. [InPersian]

13. Marzooghi R, Heidari M, Heidari E. The Impact of Educational Justice on Students' Academic Burnout in the University of Social Welfare and Rehabilitation Science, Tehran, Iran. Strides in Development of Medical Education. 2013;10(3):328-34.

14. Watson R, Deary I, Thompson D, Li G. A study of stress and burnout in nursing students in Hong Kong: a questionnaire survey. International Journal of Nursing Studies. 2008;45(10):1534-1542. https://doi.org/10.1016/j.ijnurstu.2007.11.003

15. Rudman A, Gustavsson JP. Burnout during nursing education predicts lower occupational preparedness and future clinical performance: A longitudinal study. International Journal of Nursing Studies. 2012;49(8):988-1001. https://doi.org/10.1016/j.jinurstu.2012.03.010

16. Duran A, Extremera N, Rey L, Fernández-Berrocal P, Montalbán FM. Predicting academic burnout and engagement in educational settings: Assessing the incremental validity of perceived emotional intelligence beyond perceived stress and general self-efficacy. Psicothema. 2006;18:158-164.

17. Zhang Y, Gan Y, Cham H. Perfectionism, academic burnout and engagement among Chinese college students: A structural equation modeling analysis. Personality and Individual Differences. 2007;43(6):1529-1540. https://doi.org/10.1016/j.paid.2007.04.010

18. Naami A. The relationship between the quality of learning experiences and academic burnout graduate students Shahid Chamran. Journal of Psychological Studies. 2009;5(3):117-34. [InPersian] 
19. Salmela-Aro K, Tolvanen A, Nurmi JE. Achievement strategies during university studies predict early career burnout and engagement. Journal of Vocational Behavior. 2009;75(2):162-172. https://doi.org/10.1016/j.jvb.2009.03.009

20. Gibbons $C$, Dempster M, Moutray M. Stress, coping and satisfaction in nursing students. Journal of Advanced Nursing. 2011;67(3):621-632. https://doi.org/10.1111/j.1365-2648.2010.05495.x

21. Mohammadinia N, Rezaei $M$, Sameizadehtoosi T, Darban F. Assessing suicidal ideation frequency in medical students. Quarterly Journal of Nursing version. 2012;1(1):83-91. [InPersian]

22. Inanloo $M$, Baha $R$, Seyedfatemi N, Hosseini AF. Stress Coping Styles among Nursing Students. Hayat. 2012;18(3):66-75. [InPersian]

23. Neumann Y, Neumann EF. The Robust Learning Model (RLM): A comprehensive approach to a new online university. Journal of College Teaching and Learning. 2010;7(1):27. https://doi.org/10.19030/tlc.v7i1.76

24. Marzouki $R$, Heidari $A$, heidari $M$. The relationship between quality of students learning experiences with future growth potential. Strides in Development of Medical Education. 2014;11(2):131-138. [InPersian]

25. Vahedi Sh, Hhashemi T, Shafiei Soork S. The Effect of Academic Grades, Neuroticism and Self-Regulated Learning Strategies on Academic Burnout: Testing a Conceptual Model. Knowledge and research in applied psychology. 2015;15(57):72-81. [InPersian]

26. Da Silva RM, Goulart CT, Lopes LFD, Serrano PM, Costa ALS, de Azevedo Guido L. Hardy personality and burnout syndrome among nursing students in three Brazilian universities—an analytic study. BMC Nursing. 2014;13(1):9. https://doi.org/10.1186/1472-6955-13-9

27. Tomaschewski-Barlem JG, Lunardi VL, Lunardi GL, Barlem ELD, Silveira RSD, Vidal DAS. Burnout syndrome among undergraduate nursing students at a public university. Revista Latino-americana de Enfermagem. 2014;22(6):934941. https://doi.org/10.1590/0104-1169.3254.2498

28. Papastavrou $E$, Lambrinou $E$, Tsangari $H$, Saarikoski M, Leino-Kilpi $H$. Student nurses experience of learning in the clinical environment. Nurse Education in Practice. 2010;10(3):176-182. https://doi.org/10.1016/j.nepr.2009.07.003

29. Farsi Z, Dehghan Nayeri N, Negarandeh R, Broomand S. Nursing profession in Iran: an overview of opportunities and challenges. Japan Journal of Nursing Science. 2010;7(1):9-18. https://doi.org/10.1111/j.17427924.2010.00137.x

30. Ravinipour MVZ, Afshar L, Azemian A. The Standards of Professionalism in Nursing: The Nursing Instructors' Experiences. Evidence Based Care Journal. 2014;4(1):27-40. [InPersian]

31. Heydari A, Soudmand $P$, Hajiabadi F, Armat M, Rad M. The causes and solutions of the theory and practice gap from nursing education view point: A review article. Journal of Medical Education Development. 2014;7(14):7285.[InPersian]

32. Ahmadnia E. Students' views regarding academic performance, interpersonal relationships and personal characteristics of clinical instructors, in School of Nursing and Midwifery, Zanjan University of Medical Sciences. Journal of Medical Education Development. 2014;7(13):1-8. [InPersian]

33. Mikaeili N, Afrooz G, Gholiezadeh L. The relationship of self-concept and academic burnout with academic performance of girl students. J Sch Psychol. 2013;1:124-30. [InPersian]

34. Rostami Z, Abedi MR, Schaufeli WB, Ahmadi SA, Sadeghi AH. The Psychometric Characteristics of Maslach Burnout Inventory Student Survey: A Study Students of Isfahan University. Zahedan Journal of Research in Medical Sciences. 2014;16(9):55-8. [InPersian]

35. Gharehaghaji N, Mirahadi M. Evaluating Motivation and Interest in Choosing Career or Higher Education Study among Radiology Students in Tabriz University of Medical Sciences. 2014;5(2):148-155.[InPersian]

36. Borhani F, Alhani F, Mohammadi E, Abbaszadeh A. Professional ethical competence in nursing: the role of nursing instructors. J Med Ethics Hist Med. 2010;3:3.

37. Poorchangizi B, Farokhzadian J, Abbaszadeh A, Mirzaee M, Borhani F. The importance of professional values from clinical nurses' perspective in hospitals of a medical university in Iran. BMC Medical Ethics. 2017;18(1):20. https://doi.org/10.1186/s12910-017-0178-9

$\diamond \diamond \diamond \diamond \diamond \diamond \diamond$

http://www.ejgm.co.uk 